\title{
Epoxy-based nanocomposites with amine modified single walled carbon nanotubes
}

\author{
Celina-Maria Petrea ${ }^{1 *}$ Corina Andronescu, ${ }^{1}$ Andreea Madalina Pandele, ${ }^{1}$ Sorina \\ Alexandra Garea, ${ }^{1}$ Horia lovu ${ }^{1}$ \\ ${ }^{1 *}$ Politehnica University of Bucharest; Faculty of Applied Chemistry and Materials \\ Science; Department of Polymer Science and Technology; Calea Victoriei No.149, \\ Bucharest 010072 Romania; fax: +4 02131117 96; e-mail: petrea_celina@ \\ yahoo.com
}

(Received: 06 July, 2009; published: 25 February, 2010)

\begin{abstract}
Carboxylated Single Walled Carbon Nanotubes (SWNT-COOH) were functionalized using different types of amines as modifier agents to improve the compatibility with the epoxy matrix. Covalent attachment was proved by XPS and Raman spectroscopy. TGA showed that only long chain modifier agents improved the thermal stability of modified SWNTs. Epoxy-based composites were synthesized using diglycidyl ether of bisphenol A (DGEBA) as polymer matrix and modified SWNTs as reinforcing agent.

Keywords: carbon nanotubes, epoxy composites, amine functionalization, dispersion
\end{abstract}

\section{Introduction}

Following their discovery in 1991 by lijima et al. [1] carbon nanotubes (CNTs) have attracted scientist attention from a wide range of topics. Their novel structure and remarkable properties such as high mechanical strength, high thermal and electrical conductivity, make them suitable for applications in different fields such as electronics [2], medicine [3], advanced composite materials or catalysis [4].

In addition to their particular mechanical properties single walled carbon nanotubes (SWNTs) exhibit strong side interactions between nanotubes which lead to the formation of aggregates, so that the dispersion of SWNTs in polymer matrices hardly occurs [5]. The properties of the composites depend on the final dispersion degree. The chemical functionalization of CNTs is an efficient route to solve this problem, by reducing the CNTs agglomeration and thus ensuring a compatibility with the polymer matrix. A good dispersion of the CNTs within the matrix leads to a better load transfer from matrix to the CNTs as has been shown by many recent investigations [6].

The introduction of carboxylic groups onto the CNT's surface by oxidation improves the dispersion of the CNT's both in aqueous medium and organic polymers [7-8]. Moreover, the attachment of functional groups with long chain increases the dispersion in polymer matrices. The modification of the carboxylic groups grafted on the CNT's surface may be done by amidation with amines or by etherification reactions [9]. The amidic groups on the CNT's surface may be obtained by two different routes. The first method is a two steps reaction: the first reaction is between the carboxylated CNTs (SWNT-COOH) with the thionyl chloride $\left(\mathrm{SOCl}_{2}\right)$ and the second one consists in the reaction between the product of the first step and various 
amines [10-13]. The second method uses carbodiimide chemistry for activating the carboxylic groups in the reaction with different amines [14]. The attachment of new molecules on the CNT's surface influences the photon mode vibration of CNTs, so that modifications of the electronic structure are expected [15-16].

The reinforcement of the epoxy resin with different types of CNTs gave an increase of Young modulus and tensile strength which mainly depends on the CNTs concentration within the epoxy composite [17].

The aim of this paper was to modify the SWNT-COOH with different amines, using the carbodiimide chemistry to obtain amidic groups on the SWNTs surface. In order to prove the covalent linkage of the amines, X-Ray Photoelectron Spectroscopy (XPS) and Raman spectroscopy analyses were performed. Epoxy composites were then synthesized by using functionalized SWNTs as reinforcing agents. The influence of the organic modifier on the composite $T_{g}$ value was studied.

\section{Results and discussion}

\section{XPS analysis}

The XPS survey spectra (Fig. 1) were recorded in order to identify the chemical composition of the carbon nanotubes surface. As one may observe from Table 1, the SWNT-COOH exhibit only the $C$ 1s and $O$ 1s peaks, while the functionalized samples give an additional $\mathrm{N}$ 1s peak which is proof that the reaction between the SWNT$\mathrm{COOH}$ and the amines took place.

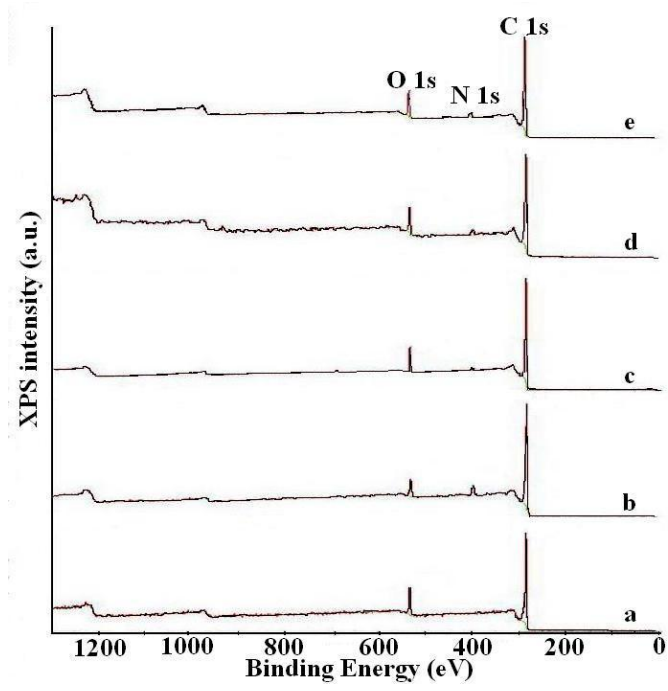

Fig. 1. XPS survey spectra of: a - SWNT-COOH; b - SWNT-EDA; c - SWNT-B100; d - SWNT-IDDA; e - SWNT-ODA.

The presence of the amidic groups on the SWNT's surface after amidation is also proved by the $\mathrm{C} 1 \mathrm{~s}$ high resolution spectra (Fig. 2). Deconvolution of the $\mathrm{C}$ 1s of SWNT-COOH show five peaks, three of the peaks always given by the SWNTs: one at $284.8 \mathrm{eV}$ assigned to the $\mathrm{C}-\mathrm{C} \mathrm{sp}{ }^{2}$ carbon atoms of the graphene sheet, the second at $285.4 \mathrm{eV}$ from defective structure region with $\mathrm{C} \mathrm{sp}^{3}$ atoms and the third at 291.5 $\mathrm{eV}$ related to the $\pi-\pi^{*}$ transitions [19]. The other two peaks correspond to the oxidized carbon species: the band at $286.8 \mathrm{eV}$ assigned to the $\mathrm{C}-\mathrm{O}$ bond from the C- 
$\mathrm{OH}$ groups obtained by the oxidation process and the band at $289.1 \mathrm{eV}$ assigned to $\mathrm{C}-\mathrm{O}$ bond from the carboxylic groups.

Tab. 1. Surface composition of carboxylated and modified SWNTs determined from the XPS survey spectra.

\begin{tabular}{llll}
\hline Sample & $\mathrm{C} \mathrm{1s}(\%)$ & $\mathrm{O} 1 \mathrm{~s}(\%)$ & $\mathrm{N} 1 \mathrm{~s}(\%)$ \\
\hline SWNT-COOH & 86.1 & 13.9 & 0 \\
SWNT-EDA & 87.3 & 7.5 & 5.2 \\
SWNT-B100 & 89.8 & 9.4 & 0.8 \\
SWNT-ODA & 86.3 & 11.5 & 2.2 \\
SWNT-IDDA & 87.0 & 10.1 & 2.9 \\
\hline
\end{tabular}
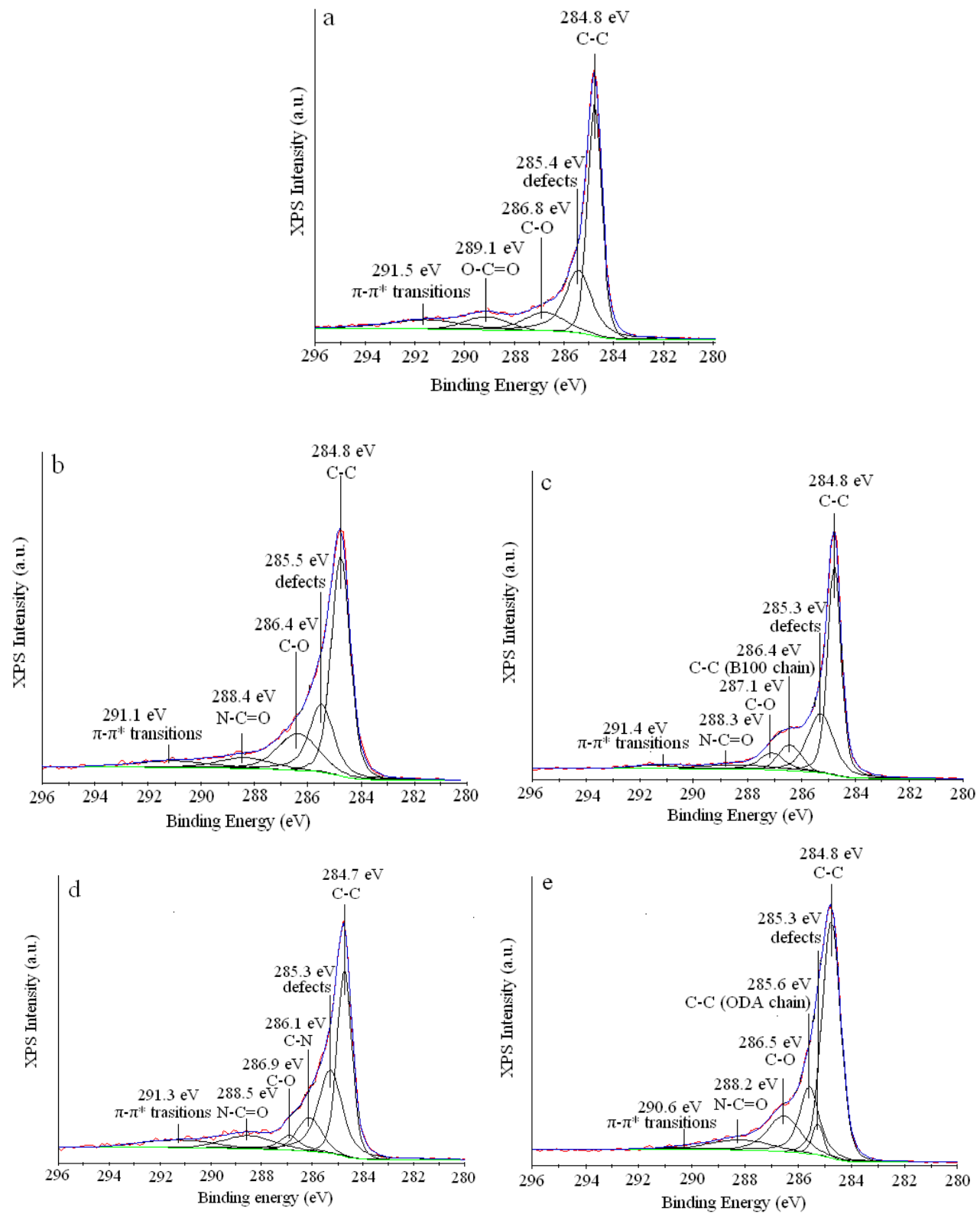

Fig. 2. XPS high resolution $C$ 1s spectra for: a - SWNT-COOH, b-SWNT-EDA, c SWNT-B100, d-SWNT-IDDA, e - SWNT-ODA. 
In the deconvolutions of the functionalized SWNT (Fig. 2), the peaks corresponding to the $\mathrm{C}-\mathrm{C} \mathrm{sp}{ }^{2}$ from the nanotube structure, $\mathrm{C} \mathrm{sp}{ }^{3}$ from defects, $\mathrm{C}-\mathrm{O}$ from the $\mathrm{C}-\mathrm{OH}$ and the $\pi-\pi^{*}$ transitions appear at almost the same energy. As one may see, the peak at $289.1 \mathrm{eV}$ assigned to the carboxylic groups from SWNT-COOH disappears when the functionalization of these groups occur and a new peak around $288.4 \mathrm{eV}$ appears, assigned to the binding energy of the carbon atoms from amidic groups. In the case of SWNT-B100 and SWNT-ODA, two new peaks are generated by the C-C $\mathrm{sp}^{3}$ bonds from the long B100 and ODA chains, one at $286.4 \mathrm{eV}$ and another at 286.5 $\mathrm{eV}$. For SWNT-IDDA a particular peak at $286.1 \mathrm{eV}$, assigned to $\mathrm{C}-\mathrm{N}$ bond from the second $-\mathrm{NH}_{2}$ group appears while for SWNT-EDA this peak cannot be revealed from the deconvolution spectra, probably due to the overlapping effect with the signal from C-O bond.

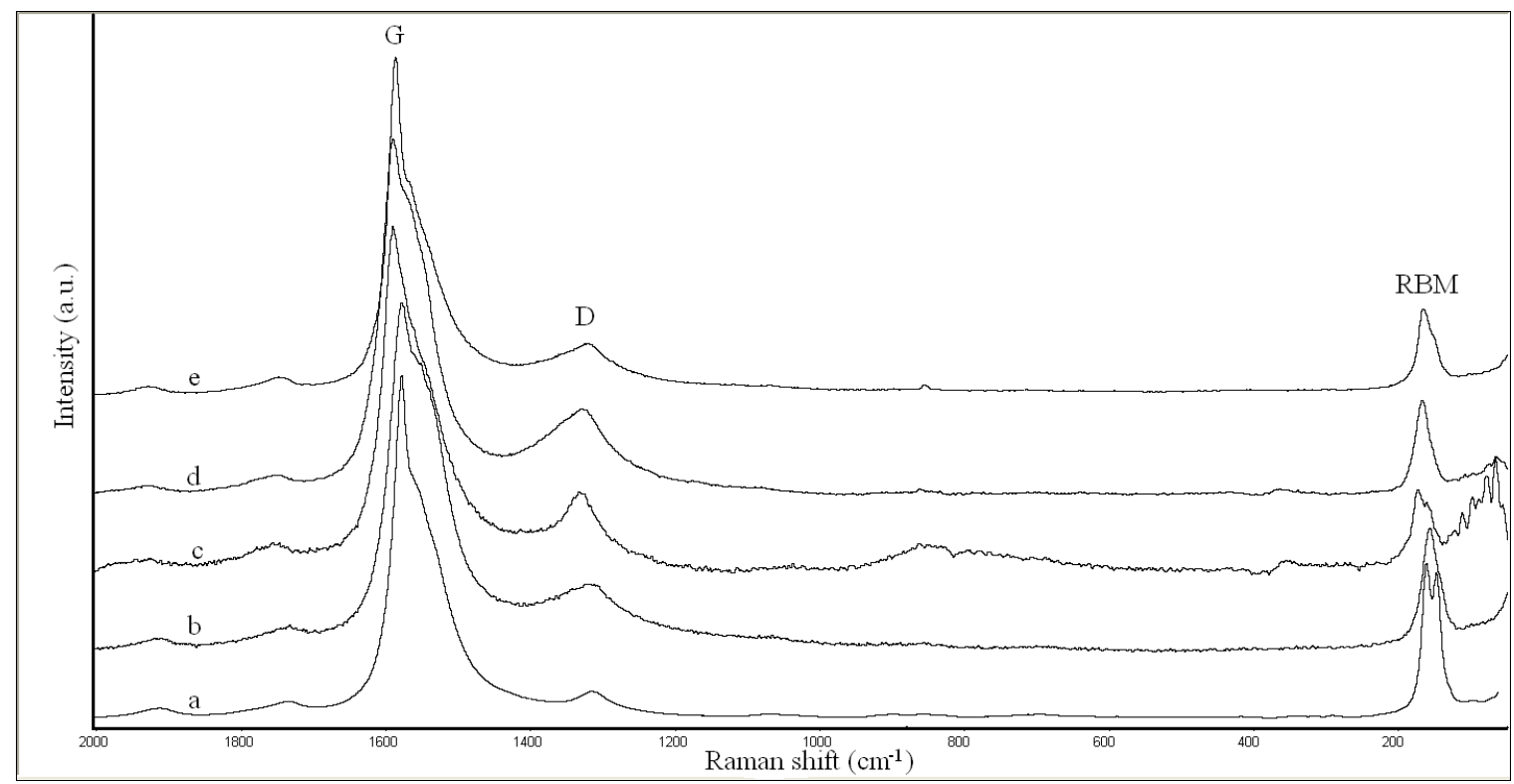

Fig. 3. The Raman spectra of: a - SWNT-COOH, b - SWNT-EDA, c - SWNT-B100, d - SWNT-IDDA, e - SWNT-ODA.

When functionalization of SWNTs occurs, the D band intensity is enhanced because of the increased structural-disorder which disturbs the extended aromatic electronic conjugation. Thus, the ratio between the intensities of $D$ and $G$ bands $\left(I_{D} / l_{G}\right)$ is correlated with the disorder degree on the SWNT surface [21].

Tab. 2. The ratio between the intensities of $D$ and $G$ peaks for carboxylated and modified SWNTs revealed from the Raman spectra.

\begin{tabular}{llll}
\hline SWNTs type & $I_{D} / I_{G}$ & D peak $\left(\mathrm{cm}^{-1}\right)$ & G peak $\left(\mathrm{cm}^{-1}\right)$ \\
\hline SWNT-COOH & 0.0757 & 1314 & 1581 \\
SWNT-EDA & 0.1820 & 1321 & 1581 \\
SWNT-B100 & 0.2335 & 1332 & 1594 \\
SWNT-IDDA & 0.2412 & 1329 & 1592 \\
SWNT-ODA & 0.1419 & 1324 & 1589 \\
\hline
\end{tabular}

The increase of this ratio for the functionalized SWNT compared with the value for SWNT-COOH (Table 2) is a proof that the organic modifiers were covalently attached 
to the SWNTs surface as $\mathrm{sp}^{3}$ type $\mathrm{C}$ atoms. Also a slight shift of these two bands is noticed due to the modification of the extended electronic structure and the reduction of the Van der Waals forces which leads to the agglomeration of the SWNTs providing smaller bundles.

\section{Thermogravimetric analysis}

The TGA tests were done on the functionalized SWNT samples and epoxy-based composite materials. The results (Table 3 ) showed that the thermal stability is improved by longer chain amines probably because these flexible chains cover the SWNTs surface and they suffer degradation at temperature forming a stable carbonaceous protective layer. The decomposition process of carboxylated nanotubes in nitrogen atmosphere starts at a lower temperature than for the other functionalized SWNTs because of the decarboxylation reaction and easy loss of the oxygenated functionality.

Tab. 3. Decomposition temperatures of functionalized SWNTs from TGA.

\begin{tabular}{llll}
\hline \multicolumn{1}{c}{ SWNT type } & $\mathrm{T}_{\mathrm{d} 3 \%}\left({ }^{\circ} \mathrm{C}\right)$ & $\mathrm{T}_{\mathrm{d} 5 \%}\left({ }^{\circ} \mathrm{C}\right)$ & $\begin{array}{c}\text { Total mass } \\
\text { loss }(\%)\end{array}$ \\
\hline SWNT-COOH & 50.4 & 111.5 & 45.3 \\
SWNT-EDA & 58.8 & 97.8 & 66.8 \\
SWNT-IDDA & 128.0 & 158.1 & 30.3 \\
SWNT-ODA & 197.6 & 240.2 & 30.3 \\
SWNT-B100 & 222.5 & 252.0 & 87.9 \\
\hline
\end{tabular}

Tab. 4. Decomposition temperatures of epoxy-based composites reinforced with functionalized SWNTs.

\begin{tabular}{lll}
\hline Systems & $\mathrm{T}_{\mathrm{d} 3 \%}{ }^{*}\left({ }^{\circ} \mathrm{C}\right)$ & $\mathrm{T}_{\mathrm{d} 5 \%}{ }^{* *}\left({ }^{\circ} \mathrm{C}\right)$ \\
\hline DGEBA/D230 & 343.9 & 360.2 \\
DGEBA/SWNT-COOH/D230 & 357.7 & 367.9 \\
DGEBA/SWNT-EDA/D230 & 335.6 & 350.1 \\
DGEBA/SWNT-IDDA/D230 & 336.2 & 346.5 \\
DGEBA/SWNT-ODA/D230 & 342.1 & 350.9 \\
DGEBA/SWNT-B100/D230 & 327.8 & 337.3 \\
\hline
\end{tabular}

${ }^{*} \mathrm{~T}_{\mathrm{d} 3 \%}$ the temperature at which the mass loss is $3 \%$

" $T_{d 5 \%}$ the temperature at which the mass loss is $5 \%$

By analyzing the epoxy-based composites reinforced with functionalized SWNTs (Table 4) one may observe that SWNT-COOH influence the initial decomposition temperature by increasing it several degrees, meaning that the functionalization of carbon nanotubes with $\mathrm{COOH}$ groups might produce covalent bonding to the matrix by reacting with epoxy groups. Even in the absence of covalent bonds, $\mathrm{H}$-bonding between $\mathrm{COOH}$ groups attached to carbon nanotubes and hydroxyl, ether or tertiary amine groups of the crosslinked network may explain the increase of thermostability of the obtained materials.

For the other systems reinforced with modified SWNTs, a decrease of the decomposition temperature with few degrees was noticed probably due to the effect 
of plasticizer caused by the unreacted curing agent (D230). This may occur if D230 molecules are replaced by the aminic groups from the chains of the modified SWNTs in the opening process of epoxy groups.

\section{DMA tests}

The DMA tests (Table 5) showed a small increase of the $T_{g}$ value for the carboxylated and modified SWNTs reinforced composites, regardless of the type of amine used as a modifier. However this increase is much lower than was expected, due to SWNTs agglomeration which was further jointed by SEM.

Tab. 5. Glass transition temperatures from DMA for epoxy-based composites (frequency $=1 \mathrm{~Hz}$ ).

\begin{tabular}{ll}
\hline Composite systems & $\mathrm{T}_{\mathrm{g}}$ in ${ }^{\circ} \mathrm{C}$ \\
\hline DGEBA/D230 & 83 \\
DGEBA/SWNT-COOH/D230 & 86 \\
DGEBA/SWNT-EDA/D230 & 85 \\
DGEBA/SWNT-IDDA/D230 & 85 \\
DGEBA/SWNT-ODA/D230 & 85 \\
DGEBA/SWNT-B100/D230 & 86 \\
\hline
\end{tabular}

SEM analysis

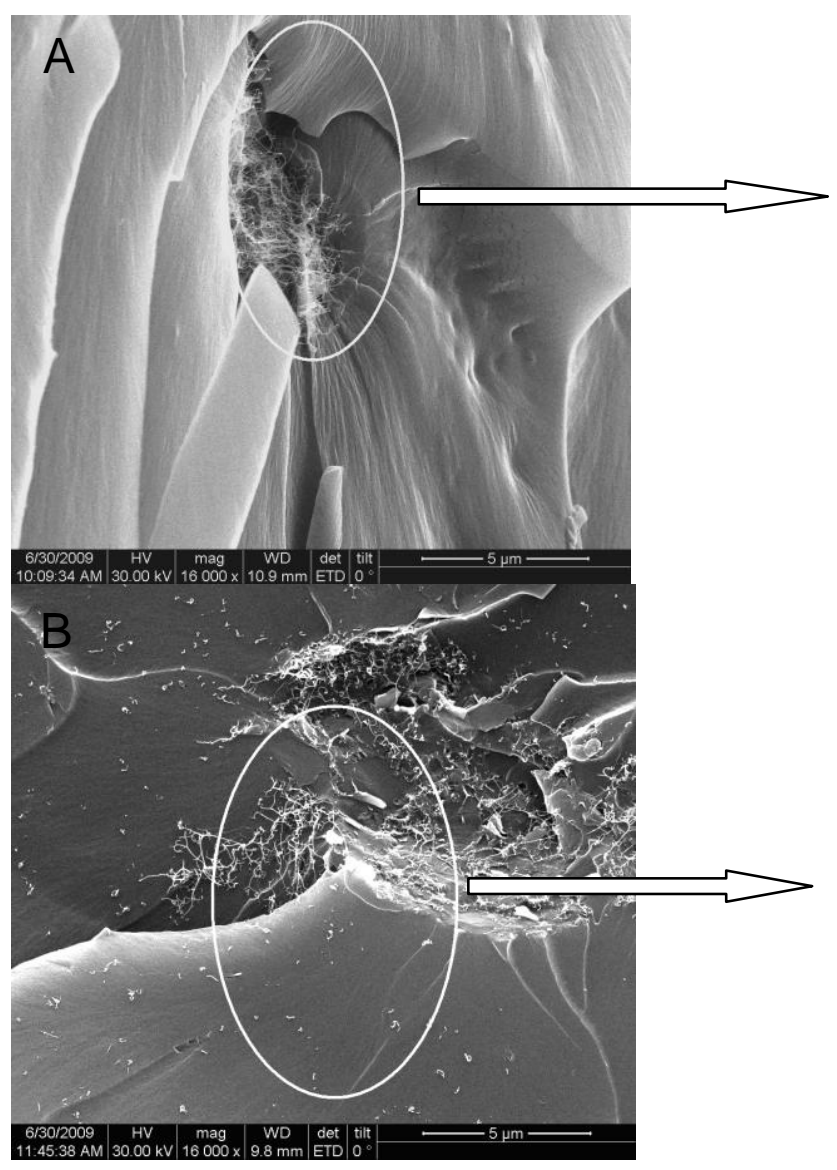

SWNT-EDA agglomeration

Well dispersed SWNT-B100

Fig. 4. Morphology of A) epoxy/SWNT-EDA and B) epoxy/SWNT-B100 systems. 
The dispersion state of the amine functionalized SWNTs was investigated using scanning electron microscopy (SEM). The SWNT-EDA reinforced composite materials shows agglomeration of the reinforcing agent, meaning that the small size of the EDA molecules are not sufficient to create an organic-inorganic compatibility with the epoxy resin, thus the SWNTs appears like long wires pulled out from the resin when the composite is fractured. On the surface of the epoxy/SWNT-B100 a better dispersion state is noticed, due to the enhanced interfacial adhesion given by the surfonamine modifier. Although this composite also shows some agglomeration of the modified SWNTs, one may see that individual SWNTs are dispersed in all the mass of the resin. Therefore the length of the organic chains attached to the SWNTs surface exhibits a significant role in the dispersion within the polymer matrix.

\section{Conclusions}

The functionalization process of SWNTs with various amines was done by a faster method using dicyclohexyl carbodiimide as activator.

The formation of the amidic groups between the $-\mathrm{COOH}$ groups from the SWNTs surface and the aminic groups from the modifiers was proved by high resolution XPS spectra. Also the attachment of long flexible aminic chains onto the SWNTs surface by covalent bonding was demonstrated from the Raman Spectra.

The nature and the length of the organic chain play an important role in the dispersion of modified SWNTs within the polymer matrix. Thus longer chains with a suitable hydrophobic-hydrophilic balance lead to a better dispersion and thus to enhanced properties of the obtained composites.

The thermostability and the $T_{g}$ value of epoxy-based composites with various aminomodified SWNTs are slightly influenced by the modifier compared with the reference (DGEBA/D230). However higher $\mathrm{T}_{g}$ values are obtained for the epoxy-based composites reinforced with surfonamine B100 which ensures a better dispersion within the DGEBA matrix.

\section{Experimental}

\section{Materials}

SWNT-COOH was purchased from Aldrich which was produced by Catalytic Chemical Vapor Deposition (CCVD) with 80-90\% purity.

Modifier agents (Scheme 1) EDA, ODA, IDDA were supplied by Aldrich. B100 and D230, were purchased from Huntsman Corporation.

DGEBA was provided by Dow Chemical.

THF, DMF used as solvents and the DCC activator were supplied by FLUKA.

The materials were used as received, without further purification.<smiles>NCCN</smiles>

Ethylenediamine (EDA)
$\mathrm{CH}_{3}\left(\mathrm{CH}_{2}\right)_{16} \mathrm{CH}_{2} \mathrm{NH}_{2}$

Octadecylamine (ODA) 
<smiles>CC(c1ccc(Oc2ccc(N)cc2)cc1)c1ccc(Oc2ccc([125I])cc2)cc1</smiles>

4,4'-(4,4'-isopropylidenediphenyl-1,1'-diyldioxy)dianiline (IDDA)<smiles>CCCCCCCCOc1ccc(CCCCCCCC)cc1</smiles>

$$
\mathrm{n}=13.5
$$

Nonylphenoxy polypropyleneoxyamine (B100)<smiles>[Y][R]#[R]</smiles>

Polyether amine (D230)

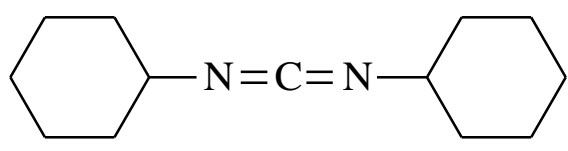

N,N'-Dicyclohexyl carbodiimide (DCC)<smiles>CC(C)(c1ccc(OCC2CO2)cc1)c1ccc(OCC2CO2)cc1</smiles>

Diglycidyl ether of bisphenol A (DGEBA)

Scheme 1. The chemical formula of the reactants.

\section{Functionalization}

In order to activate the carboxylic groups, SWNT-COOH was stirred with DCC in an ultrasonic bath for $1 \mathrm{~h}$ at $40^{\circ} \mathrm{C}$. Then the amine was added in excess, $1 \mathrm{ml}$ THF was used as solvent and the sonication process was maintained for $2 \mathrm{~h}$ at $30-35{ }^{\circ} \mathrm{C}$. The products were purified by washing on teflon membrane $(\mathrm{d}=0.2 \mu \mathrm{m})$ two times with THF and two times more with THF-DMF mixture and then dried for 2 days under 25 $\mathrm{mm} \mathrm{Hg}$ vacuum. Thus regarding the amine used the following functionalized SWNTs were obtained: SWNT-EDA, SWNT-ODA, SWNT-B100 and SWNT-IDDA.

\section{Composites synthesis}

DGEBA and modified SWNTs (0.3 wt.\%) were sonicated for $120 \mathrm{~min}$ to better disperse the reinforcing agent, keeping the temperature at $30{ }^{\circ} \mathrm{C}$. After sonication, D230 (33 wt. \%) was added to the epoxy/SWNT mixture, further degassed and cooled at room temperature. The obtained composite was poured into a mould and crosslinked for $3 \mathrm{~h}$ at $60^{\circ} \mathrm{C}$ and postcured for $1.5 \mathrm{~h}$ at $100^{\circ} \mathrm{C}$.

\section{Characterization}

-Thermogravimetric Analysis (TGA)

TGA tests were done on Q500 TA equipment using nitrogen and a heating rate of 10 ${ }^{\circ} \mathrm{C} / \mathrm{min}$, from room temperature to $800{ }^{\circ} \mathrm{C}$. 


\section{-Dynamic Mechanical Analysis (DMA)}

DMA tests were run on a TRITEC 2000 B instrument. Samples were analyzed in bending mode at a frequency of $1 \mathrm{~Hz}$. Data were collected from room temperature to $180^{\circ} \mathrm{C}$ at $5^{\circ} \mathrm{C} / \mathrm{min}$ heating rate.

\section{-Raman Spectroscopy}

Raman spectra were registered on a DXR Raman Microscope from Thermo Scientific using a $633 \mathrm{~nm}$ laser line. The laser beam was focused with the 10x objective.

\section{-X-ray photoelectron spectroscopy (XPS)}

XPS analysis was performed on a K-Alpha instrument from Thermo Scientific, using a monochromated Al $\mathrm{K}_{\alpha}$ source $(1486.6 \mathrm{eV})$, at a pressure of $2 \times 10^{-9} \mathrm{mbar}$. Charging effects were compensated by a flood gun, and binding energy was calibrated by placing the $\mathrm{C}$ 1s peak at $284.8 \mathrm{eV}$ as internal standard. The survey spectra were registred using a pass energy of $200 \mathrm{eV}$ and for the high resolution spectra $20 \mathrm{eV}$. Deconvolution of $\mathrm{C} 1 \mathrm{~s}$ peaks was done after substraction of Shirley background.

\section{-Scanning electron microscopy (SEM)}

SEM analysis was done using a Quanta $F$ (FEI) instrument, provided with field emission electron gun, $1.2 \mathrm{~nm}$ resolution and X-ray energy dispersive spectrometer having an accelerating voltage of $30 \mathrm{kV}$. For better contrast, fresh fracture surface was covered with gold layer.

\section{References}

[1] lijima, S. Nature 1991, 354, 56.

[2] Bogani, L.; Wernsdorfer, W. Inorg. Chim. Acta 2008, 361, 3807.

[3] Kohli, P.; Martin, C. Curr. Pharm. Biotechnol. 2005, 6, 35.

[4] Kim, M.; Park, Y-B.; Okoli O.; Zhang, C. Compos. Sci. Technol. 2009, 69, 335.

[5] Bhalchandra, K.; Vijayamohanan, P. Appl. Surf. Sci. 2008, 254, 4936.

[6] Hussain, F.; Hojjati, M.; Okamoto, M.; Gorga, R. J. Compos. Mat. 2006, 40, 1511.

[7] Kakade, B.A.; Pillai, V.K. Appl. Surf. Sci. 2008, 254, 4936.

[8] Shen, J.; Hu, Y.; Qin, C.; Ye, M. Composites: Part A 2008, 39, 1679.

[9] Basiuk V., Basiuk A. Encyclopedia of Nanoscience and Nanotechnology, Edited by H.S.Nalwa, Volume 1: pages: 761-776

[10] Petrea, C.M.; Andronescu, C.; Pandele, A.M.; Garea, S.A.; lovu, H. Mat. Plast. 2008, 45, 320 .

[11] Dettlaff-Weglikowska, U.; Benoit, J.M.; Chiu, P.W.; Graupner, R.; Lebedkin, S.; Roth, S. Curr. Appl. Phys. 2002, 2, 497.

[12] Wang, Y.; lqbal, Z.; Malhotra, S.V. Chem. Phys. Lett. 2005, 402, 96.

[13] Gabriel, G.; Sauthier, G.; Fraxedas, J.; Moreno-Manas, M.; Martinez, M.T.; Miravitlles, C.; Casabo, J. Carbon 2006, 44, 1891.

[14] Feng, L.; Li, H.; Li, F.; Shi, Z.; Gu, Z. Carbon 2003, 41, 2385.

[15] Bae, J.H.; Shanmugharaj, A.M.; Noh, W.H.; Choi, W.S.; Ryu, S.H. Appl. Surf.

Sci. 2007, 253, 4150.

[16] Fantini, C.; Pimenta, M.A.; Strano, M.S. J. Phys. Chem. C 2008, 112, 13150.

[17] Ci, L.; Bai, J. Compos. Sci. Technol. 2006, 66, 599.

[18] Suave, J.; Coelho, L.; Amico S.; Pezzein S. Mater. Sci. Eng., A 2009, 509, 57.

[19] Estrade-Szwarckopf, H. Carbon 2004, 42, 1713. 
[20] Dresselhaus, M.S.; Dresselhaus, G.; Saito, R.; Jorio, A. Phys. Reports 2005, 409, 47.

[21] Fantini C.; Jorio A.; Santos A.P.; Peressinotto V.S.T.; Pimenta M.A. J. Phys., Chem. 2008, 112, 13150. 